\title{
What drives political participation? Motivations and Mobilization in a Digital Age
}

\author{
Abstract \\ The article provides insights into the driving forces that underpin new forms of political \\ participation. Digital technologies offer opportunities for engaging in a wide range of civically- \\ oriented activities, whether liking or sharing political content, joining online political \\ communities or joining discussions, each can contribute to deeper democratic engagement \\ and, for the individual, act as a pathway towards further civic participation. Conventional acts \\ of political participation, demonstrating, petitioning and voting, are argued to be driven \\ primarily by intrinsic motivations relating to self-efficacy and empowerment as the individual \\ feels they can have influence over decision makers. Little research explores whether similar \\ motivations drive participation in less conventional acts, as well as whether mobilisation \\ attempts via social media by peers or political organisations mediate those motivations. \\ Drawing on data from a survey among a representative sample of the UK electorate, we find \\ the offline and online spheres of agency as still fairly distinct. Intrinsic and extrinsic \\ motivations both matter but extrinsic motivations, following norms of behaviour within \\ networks and supporting the activities of peers, have the strongest explanatory power \\ independent of the sphere of activity. The mediating effect of mobilisation tactics has a \\ minimal effect on extrinsic motivations, online or offline, but online intrinsic motivations lose \\ their explanatory power. This finding suggests online political acts are carried out due to \\ mobilisation, although as intrinsic factors offer little explanatory power these acts may lack \\ meaning to the individual. We also found that campaign organisations are the most powerful \\ mobilisers perhaps suggesting social media users are most likely to perform simple acts in \\ support of non-contentious causes.
}




\section{Introduction}

Political participation can no longer be purely defined in terms of high effort, offline acts with "the intent or effect of influencing government action - either directly by affecting the making or implementation of public policy or indirectly by influencing the selection of people who make those policies." (Verba, Schlozman \& Brady, 1995: 38). Political participation now covers an array of forms which includes the acts Verba et al. describe, such as voting, petitioning governments, contacting elected representatives and taking part in demonstrations, as well as non-conventional acts performed using digital technologies which appear geared more towards expressing a view, supportive or otherwise, than influencing decision makers (De Zúñiga et al., 2012; Bimber \& Copeland, 2013; Gibson \& Cantijoch, 2013). Most conventional acts can be performed using digital platforms, however social media not only facilitates participation in its conventional understanding but also in creating or joining communities which transcend state or national boundaries, starting or contributing to discussions, advertising support for causes, and promoting the work of a range of political organisations and campaigns in national and global dimension. Digital technologies provide a range of new means for engaging in civically-oriented forms of behaviour.

Political organisations encourage supporters to engage in these forms of behaviour via digital platforms. Political parties, non-governmental and civil society organisations attempt to draw citizens into promoting their campaigns, harnessing their dedication to a cause or the organisation (Author et al., 2015). The interplay of attitudes towards a participatory act, the organisation promoting that act, and beliefs and positions elicited through persuasive communication represent highly complex cognitive processes (Leighley, 1995). The complexity is increased in the digital age, a broader range of factors can heighten the propensity to take part in forms of participation, and research suggests the use of digital technologies can provide pathways into higher cognitive engagement and participation (De Zúñiga et al, 2012). Little research, however, captures how stimuli received via digital technologies impact on the inclinations of individuals to create the conditions for political participation. While much research has explored who participates and what they do, there is a gap in understanding the power of mobilisation tactics.

Our research explores what motivates citizens to pursue suites of participation, specifically testing the power of intrinsic and extrinsic motivations and the extent these are mediated by persuasive communication. Given the evidence showing a decline in participation in a range of forms of civic life (Martin, 2012), it is crucial to understand what stimulates citizens to perform civically-oriented actions. Our research is conducted within a context when political engagement should be high. Elections are usually times of high politicization of the UK 
public sphere (Swanson \& Mancini, 1996) with evidence that digital technology expands the public sphere and fuels engagement (Enli \& Skogerbø, 2013). The 2015 UK political scene, in the aftermath of the European parliamentary election (May 2014), the referendum on independence for Scotland (September 2014), and the close proximity of opinion polls showing deadlock between the major parties, suggests an atmosphere for even greater political engagement. The media focus on the continued rise of Euroscepticism, with a rightwing anti-EU party winning most seats in the European parliament initiated a debate on the UK's membership of the EU onto the election agenda. Controversy also surrounded the nature of the devolution settlement for Scotland following the close victory of the No campaign and the opening of debates over parity between the four nations of the UK. The ramping up of media speculation regarding the outcome of the forthcoming contest, and high chance of protracted coalition negotiations, meant voter turnout was predicted to be high. While an unusual set of circumstances, this context of high interest and potentially higher participation allows us to determine what levels of participation actually existed and what motivational factors determined participation. This study is based on data drawn from a representative survey of UK citizens designed to explore the extent of participation across a range of acts and the motivations for performing each action. We proceed to conceptualise motivations and mobilisation prior to providing details on the methodology, presenting findings and offering pointers for further research.

\section{Motivations and Mobilisation}

Motivations to perform any activity can be broadly defined as intrinsic, pleasure-seeking, or extrinsic, for the benefit of others. In each case persuasive communication can engender beliefs that an action can lead to the desired impact. Within the context of UK politics, organisations seek to persuade citizens to support the organisation, join its campaigns and provide financial and physical resources (Fisher et al., 2014). Attempts at mobilising supporters are highly strategic (Rosenstone \& Hansen, 1993) and have accelerated significantly as a result of the widespread adoption of social media (Vaccari, 2013). Organisations not only seek to mobilise supporters directly, but also encourage existing activists to mobilise those within their digital networks. The revised two-step flow model for political campaigning (Norris \& Curtice, 2008) demonstrates how organisations utilise the affordances of social media to mobilise their supporters to, in turn, persuade and mobilise their followers. Social media allows any user to play the role of activist, even on a single occasion, they can post content about a political cause or issue, be it their own content, content from other users, content from media or content from political organisations. Each of these actions, by intention or by accident, can have a mobilising impact on people within their online networks, with the greater the size of a network the greater the opportunity to be 
mobilised (De Zúñiga et al., 2014). Theocharis (2015: 5) uses the term digitally networked participation to describe "the act of activating one's personal networks via digital media with the aim to mobilize others for social or political purposes [which] constitutes a mode of participation with different manifestations". The effectiveness of differing mobilisation practices is however largely unknown. It might be expected that such tactics would only be successful among the most dedicated supporters, yet the ubiquity of cues to act may mean social media is able to accelerate participation levels across a wider milieu of users. The extent that digitally networked participation occurs and the interplay between motivations and mobilisation tactics is the question at the heart of this research.

Motivations, as explained by self-determination theory, represent the interplay between personal attitudes towards a specific action and external persuasion (Ryan \& Deci, 2000a). Intrinsic motivations hinge upon personal attitudes which provide hedonic evaluations of actions (Shang et al., 2005) assessing for example whether an act is interesting, enjoyable or providing satisfaction (Ryan \& Deci, 2000b). Extrinsic motivations however suggest people seek the approval of and rewards from others (Deci, 1971) and, using experimental conditions, it is proven that the greater reward the higher the likelihood of action (Deci et al., 1999). Subsequent studies highlight the importance of 'bottom-up' encouragement from peers (Vallerand \& Lalande, 2011) or the expectation of gaining approval from peers (Madden et al., 1992), suggesting the importance of extrinsic, communal (Omoto et al., 2010) or prosocial (Grant, 2008) motivations are important in explaining engagement in civic. In contrast research shows for some activists the dominant motivations are intrinsic, seeking enjoyment, self-realization and personal well-being (Klar \& Kasser, 2009). These studies hint further that intrinsic and extrinsic motivations combine to govern behaviour but the strength of each set of motivations may vary dependent upon the behaviour. Ryan and Deci (2000b) recognise that where there are combinations of intrinsic and extrinsic motivations, for example when an expectation of rewards makes a task personally enjoyable and fulfilling, an action is more likely to be taken. Degli-Antoni (2009) found volunteers seek to have a positive effect on others through their efforts, and feel self-fulfilled; however they are also motivated by gaining recognition from peers and earning social capital. The suggestion is therefore that while differing actions may elide with differing levels of both intrinsic and extrinsic motivations each set of motivations will impact upon the other, earned social capital leads to feelings of self-fulfilment for example, an individual will be most likely to perform an action when they have strong intrinsic and/or extrinsic motivations. The strength of motivations may also be highly dependent on the mobilisation factors that spur an individual into a particular behaviour. 
The extent people become motivated through the mobilization strategies of political organisations or peers within their networks via social media is an issue of some debate. The mobilization thesis argues that access to digital technologies has the capacity to draw new participants into civic life (Stanley \& Wear, 2004), particularly among younger citizens (Hirzalla et al., 2010). This thesis suggests extrinsic motivations are likely to dominate. In contrast other studies show digital technologies reinforce the patterns of behaviour of existing participants and so offer complementarity; strengthening commitment by providing further means to pursue forms of activism (Dutta-Bergman, 2006). The reinforcement and complementarity theses suggest intrinsic motivations would be most dominant. In reality studies often find mixed results with digital technologies facilitating reinforcement and mobilization among differing groups of users of digital platforms (Nam, 2012). The complex decision making processes informing behavioural decisions are a recognised phenomenon in consumer behaviour literature (Madden, Ellen \& Ajzen, 1992) but has been strikingly absent from discussions of civically-oriented actions. Without in-depth studies at the level of the individual it is impossible to gauge whether intrinsic motivations, supporting reinforcement and complementarity theses, or extrinsic motivations, supporting the mobilisation thesis, govern any specific decision to act. However, studying a large group of individuals one would expect that to differing extents both sets of motivations would be important albeit at different levels dependent upon whether the individuals act due to personal reasons or based on cues they receive. We therefore argue that:

H1. Regardless of the form or sphere of participation we will find a positive influence from both intrinsic and extrinsic motivations on political participation regardless of other explanatory factors.

\section{Motivations, mobilisation and participation}

Research on election campaigns (Author, 2014) and the campaigns of civic society organisations (Enjolras et al., 2013; Guo \& Saxton, 2014) show both build community spaces, encourage supporters to join those spaces and then seek to mobilise those supporters to perform actions to benefit the organisation and its campaign. Social media has become a significant battleground for all political organisations, in particular civic society organisations (Acensio \& Sun, 2015). Studies over the two last decades have largely treated online and offline as two distinct spheres of activity, although research has found hyper active citizens taking part in both offline and digital environments, there is still a significant number of studies suggesting the existence of participation patterns taking place within one single sphere (Polat, 2005; Quintelier \& Vissers, 2008; De Zúñiga \& Valenzuela, 2011; Vissers \& Stolle, 2014). 
While debates rage, we follow a direction in research which argues "a distinction between online and offline political activity should be maintained" (Vissers \& Stolle, 2014: 950). The distinction chimes with arguments suggesting that as online mobilisation leads only to online forms of participation, people's propensity to participate becomes channelled into activities which are shallow and effortless (Morozov, 2012). Yet research consistently shows online mobilisation has a lower if not a minimal effect in encouraging offline forms of participation (Quintelier \& Vissers, 2008). In the UK, studies largely reinforce this finding (Ward et al, 2003; Di Gennaro \& Dutton, 2006) although more recent research has found more complex suites of participation exist where the online and offline spheres are bridged (Gibson \& Cantijoch, 2013). Again, however, there is no indication of the motivations underpinning suites of activities. Studies show online forms of political engagement, such as active information seeking online (De Zúñiga et al., 2009; De Zúñiga et al., 2012) and goal oriented forum use (Gibson \& Cantijoch, 2013; Semaan et al., 2015), positively predict further participation online and offline, however these studies were not designed to understand why. The traditional view of political participation, as activities directed to influencing the actions of composition of a legislature, offer a view of participants as feeling empowered and act in order to realize their potential as citizens. The crucial factor which appears to drive political participation is commitment, to a cause or organisation, which suggests intrinsic motivations, relating to the pursuit of self-fulfilment and self-realization drive behaviour. We therefore hypothesise:

H2a. Intrinsic motivations will have greater explanatory power over participation occurring within the offline sphere (as this involves greater effort and resources, and therefore planning, so personal attitudes towards the action and its outcomes will dominate)

While intrinsic motivations are considered crucial where an action involves effort, this may not be the same within online environments. The interactive affordances of digital platforms have been found to offer extrinsic motivations for participation. Studies find that while much social activity is geared around being entertained or informed, those who join Facebook communities do so in order to socialize, and enhance their reputation among peers (Park et al., 2009). Similarly interaction, whatever the subject matter, within communities is undertaken in pursuit of social capital (McClurg, 2003). Indeed the primary motivations of bloggers are to influence others and build a reputation (Ekdale, 2010). While these factors relate to intrinsic motivations, such as increasing self-esteem, the main motivations are extrinsic. In order to earn social capital there must be an expectation of rewards from others suggesting external encouragement will be an important spur to action (Kriesi, 2008). The role of organisations as mobilizing forces could therefore be crucial, in particular through empowering supporters by providing means to complement commitment through activism 
(Sotirovic \& McLeod, 2001). Mobilisation tactics, therefore, are likely to make appeals which bolster intrinsic motivations by engendering feelings of self-efficacy (Condon \& Helleque, 2013).

Defining suites of participation is problematic, particular given that it is becoming less possible to separate the online and offline spheres of activity ${ }^{1}$. For example petitioning or lobbying elected representatives is an action that can be performed face to face, via mail, email or even social media. Studies have broken down online participation into clusters, for example receiving news, acting as party activists, posting political comments or discussing politics and contacting representatives (Gibson \& Cantijoch, 2013). While research drawing on self-determination theory suggests there are relationships between intrinsic and extrinsic motivations (Ryan \& Deci, 2000a; 2000b), research on online participation suggests extrinsic motivations are dominant and likely to feed intrinsic motivations. We therefore argue:

$\mathrm{H} 2 \mathrm{~b}$. Extrinsic motivations will have greater explanatory power over participation occurring within the online sphere (as mobilisation and action can occur almost simultaneously).

Social media also facilitates accidental exposure to news and political content and permits all users to publicly show their agreement or disagreement through posting content and commenting. In terms of Facebook's likes and shares or Twitter's retweet function this can involve nothing more than a single click. Exposure to political content from peers or directly from organizations or activists both predict online and offline participation, viewing content shared by peers is a stronger predictor of online participation, while direct communication from an organisation predicts online and offline participation (Tang \& Lee, 2013). These findings build upon studies which have shown accidental exposure to news can lead to a heightened propensity to participate (De Zúñiga et al., 2012; Kim et al., 2013; Diehl et al., 2015) and at the very least can reduce gaps in the levels of interest and engagement (Valeriani \& Vaccari, 2015). Social pressure, applied by peers via social media, to act in a certain way is equally seen as a predictor of participation, in particular when an action is seen to have broader societal benefits (Panagopoulos, 2013) and applied via "specific networks of informal sociability" (Lowndes, 2004: 61). In other words close peers in closed or bounded networks such as friends groups or support communities provide the extrinsic motivations that can drive participation. Studies of the effects of social media usage on the propensity to participate from different perspectives arrive at contrasting results ranging from strong to adverse effects (Theocharis \& Lowe, 2015). Some studies highlight that the form of

\footnotetext{
${ }^{1}$ In order to understand what behavioural clusters exist across the spheres within our sample correlations (Appendix: Table 1) and confirmatory factor analysis (Appendix: Table 2) were performed delivering two clusters which map into online and offline spheres of activity; this excludes signing petitions which maps to both clusters.
} 
social media usage matters, for example positive experiences from engaging in issuespecific activism increases the propensity to participate further (Vraga et al, 2015) while others suggest it is the composition of an individual's network (Lupton et al, 2014), its size, interactive dynamics and heterogeneity (Huckfeldt, 2014). The inconsistent results demonstrate the importance of asking about a range of participatory actions, their motivations and the forms of mobilisation received in order to fully distinguish what forms of mobilisation stimulate which motivations. We therefore hypothesise:

$\mathrm{H} 3 \mathrm{a}$. The predictive strength of intrinsic motivations will not be mediated by the mobilisation from political parties, non-electoral organisations and peers.

H3b. The predictive strength of extrinsic motivations will be mediated by mobilisation from political parties, non-electoral organisations and peers.

\section{Methodology}

There is a general lack of data on the motivations driving political participation and the mediation of motivations by mobilisation via social media. We ran an online survey with Opinium Research on a sample of 18+ year olds representative for the United Kingdom $\mathrm{N}=2037$ (the Northern Ireland respondents were excluded due to the missing variables within party identification questions leaving the sample of $N=1982$ ). The survey was conducted one month prior to the start of the six-week 2015 parliamentary election campaign 24-27 February 2015. The questionnaire was sent out to a stratified sample of those registered on the Opinium Research database (40 000 e-mails), the stratification (by age, gender, region and social class) was used to ensure representativeness. The CAWI method was employed with the response rate of 29 per cent (out of 7126 invitations sent).

\section{Dependent variables}

Following Quintelier \& Vissers (2008) and Vissers \& Stolle (2014), as well as given that our respondents' reported behaviour map to two distinct suites (see Appendix), we use the spheres of activity, offline or online, as a dependent variable to ascertain what differences can be found between motivations within the offline and online environments.

The index of offline and online political activities are based on questions asking if in the last 12 months they have performed any of the following: [offline] "boycotted a company or product" $\mathrm{N}=347$ (17.5\%), "joined/rejoined a political party" $\mathrm{N}=119(6 \%)$, "contacted an elective representative" $\mathrm{N}=314(15.8 \%)$ (even if this activity could be perform offline and online in EFA analysis it loaded lower than .3 on the online index), "taken part in a demonstration" $\mathrm{N}=130$ (6.6\%); [online] "commented about politics on social media" $\mathrm{N}=320$ 
(16\%), "follow political non-governmental political organization or charity on SM" N=278 (14\%), "shared political content on SM" N= 243 (12\%), "follow political party/MP/candidate on SM" N=199 (10\%). Further, based on Confirmatory Factor Analysis coefficients (please see Tables 2 in Appendix), the questions were recoded into two indexes: offline political participation $\alpha=.782(\mathrm{M}=.47 \mathrm{SD}=.89)$; and online political participation $\alpha=.714(\mathrm{M}=.51$ $\mathrm{SD}=.89)$.

\section{Independent variables}

Motivations: for each of the political activities respondents indicated the level ((4) strongly agree to $(0)$ strongly disagree) to which motivations are driving their engagement in each activity. Two indices were created drawing on Ajzen and colleagues' theory of reasoned action and theory of planned behaviour (Madden et al., 1992) which highlight the importance of behavioural beliefs (underpinning intrinsic motivations) and normative beliefs (underpinning extrinsic motivations). Our survey questions were adapted for the political participation context based on procedures developed by Ajzen and publicly available at http://people.umass.edu/aizen/tpb.html.

The Intrinsic motivation index (IMI) is based on a combination of feeling good, having a positive self-image and feelings of self-efficacy factors which contribute to self-satisfaction (Ryan \& Deci, 2000a). The following questions were asked for each political activity "I personally feel good for taking part in this activity", "I feel that this activity is the sort of thing that my friends and family would respect me for", "I feel I can influence others", "I feel I can influence policy makers". The Extrinsic motivation index (EMI) "Others benefits from people like me taking part in this activity", "A number of my friends are also taking part in this activity", "I feel inspired by my friends to take part in this activity" link to the instrumentalist nature of these motivations being concerned with benefitting others as well as expecting rewards through conforming with norms prevailing within peer networks (Deci, 1971). Indexes were calculated separately for offline and online participation: IMI for offline activities (16 items, range 0-64, $\alpha=.963, M=27.4, S D=16.5$ ); IMI for online activities (16 items, range $0-64, \alpha=.975, M=23.6, S D=17$ ); EMI for offline activities (12 items, range 0-48, $\alpha=.946$, $M=18.6, S D=11.9$ ); EMI for online activities (12 items, range 0-48, $\alpha=.961, M=17.2$, $\mathrm{SD}=12.6)$.

Mobilisation / encouragement: frequency ((4) frequently to (0) never) of encountering the following mobilisation: "I see friends sharing and linking content on social media' or' I received encouragement via social media from friends to like or join political campaigns"( $\mathrm{M}=2.49, \mathrm{SD}=2.53$, max=8), "I received encouragement via social media from political parties to like or join their campaigns" $(\mathrm{M}=1.08, \mathrm{SD}=1.3$, $\max =4)$, "I received 
encouragement via social media from campaign organization to like or join their campaigns" $(\mathrm{M}=1.25, \mathrm{SD}=1.4, \max =4)$.

\section{Control variables}

Socio-demographic variables: gender with female (53\%, reference group); age continuous variable $(M=46.4 S D=16.3)$; education measured as dummy variable for those with university education (46\%) and with lower than university education (54\%, reference group); social grade (ordered variable) is measured according to National Readership Survey (NRS) (A group 11\%, B 26\%, C1 30\%, C2 12\%, D 9\%, E 12\%); employment is a dummy variable with those being fully or partially employed (66\%, otherwise is a reference group).

Political variables: Party identification is measured by whether respondents could offer a clear sense of which party would earn their vote, given that the campaign had not started and the election was three months later this provides a sense of their partisan leaning. Party identification a dummy variable $1=$ having party identity $(73 \%$, otherwise is a reference group); Political discussion measured as dummy for those discussing politics with friends or family ( $51 \%$, otherwise is a reference group) this is also used as a proxy for political interest.

\section{Results}

\section{Modelling offline and online political participation}

In order to understand the role intrinsic and extrinsic motivations have, as well as the mediating role of mobilization attempts sent via social media by political parties, campaigning organizations and friends, regressions and path analysis were run separately for different participatory patterns. The offline and online participatory indexes are presented in models without mobilisation effects (models A) and with mobilisation effects (models B).

The data from regression analysis shows that demographic characteristics have differential effects for explaining offline and online participatory patterns. Education remains a strong predictor, regardless of the participatory activities or mediation by encouragement, with those being more educated also engaging more. Gender is a significant explanatory characteristic for online activities only (males being marginally more active $\beta_{\mathrm{RA} \text { (regression model A) }}$ $=.067 \mathrm{p}<.05$ ). The gender effect is mediated, however, by mobilisation. When we take into account being encouraged to act online, the gender gap diminishes. This finding suggests males are slightly more likely to engage in political participation, but encouragement via social media may have a greater effect on females. As could be expected, age has a differing impacts depending on whether participation is offline or online, older respondents are definitely more likely to engage in traditional offline activities $\left(\beta_{R A}=.004 p<.05\right)$, 
surprisingly the effect is even stronger when receiving encouragement via social media $\left(\beta_{\mathrm{RB}}=.006 \mathrm{p}<.000\right)$. Age has no statistically significant impact on online participation suggesting that firstly, young people are more eager to engage online than offline, but also that age-related differences visible in earlier studies (Martin, 2012), most probably due to a generational digital divide (Hwang \& Park, 2013), has diminished. The diminishing age gap may result from the greater ease of participating in online forms of political activism. Those from a lower social class tend to be less likely to engage in offline participation $\left(\beta_{R A}=-.027\right.$ $\mathrm{p}<.05)$, the gap remains regardless of the source of mobilisation. As for online participation, social class is not significant in model $A$, however in model $B$ encouragement via social media appears to offer the potential to mobilise lower class citizens into political participation online $\left(\beta_{R B}=.021 p=.07\right)$. As could be expected political variables (party identity and political discussion) play statistically significant and positive roles on participation rates regardless of the form of participation and independent of mediation by receiving encouragement.

Table 1 here please

We find interesting contrasts when exploring the explanatory power of the two motivational forces. While both sets of motivations have positive explanatory power for offline political participation, extrinsic motivations appear to be dominant. This is contrary to expectations. However, when focusing on online forms of political participation our expectations are confirmed by the significantly higher explanatory power of extrinsic motivations. However when mobilisation factors are included the significance of intrinsic and extrinsic motivations diminish, and for intrinsic motivations for online political participation they disappear entirely. We suggest therefore that while intrinsic and extrinsic motivations play a role they are heavily mediated by mobilisation, in particular those received from campaign organisations. Actions taken may, in fact, not have lasting personal significance, but rather they have immediate value resulting from a prompt from an organisation one feels close to. The explanatory power of party proximity, though significant across all models, may suggest parties are one but not the most important factor for encouraging political activism even in the lead up to a major national election.

Hypotheses $\mathrm{H} 1$ suggests there should be a positive effect on participation from individuals' motivations, regardless whether they are intrinsic or extrinsic, however previous studies suggest that intrinsic motivations should be stronger than extrinsic at least for offline forms of political participation (Hypothesis H2). One may assume that self-efficacy or a feeling that individuals' actions may influence policy or other citizens (IMI) or a feeling of group belonging and collective (connective) actions (EMI) have a positive and constant effect on engaging, regardless of any other variables. Furthermore, our assumption was that forms of 
mobilisation received from any actor (peers (social media friends) or organizations (political party, campaigning organization)) should have reinforcing power on the participatory activities. Thus we claim that the complementary effect of mediation, with statistically significant direct and indirect effects of motivations without/with encouragement should exist (Zhao et al 2010). Our data only partially confirms these hypotheses and complementary assumptions.

We find a stable, statistically significant, positive and non-mediated effect from extrinsic motivations on any forms of political participation $\left(\beta_{\mathrm{RA}}=.019, \beta_{\mathrm{RB}}=.012 p<.000\right.$ for offline and $\beta_{\mathrm{RA}}=.019, \beta_{\mathrm{RB}}=.012 \mathrm{p}<.001$ for online). The result is strong regardless whether participation takes place within an offline or online sphere, confirming hypothesis $\mathrm{H} 2 \mathrm{~b}$, but particularly showing the importance of extrinsic motivations for driving online participatory actions. On the contrary, intrinsic motivations have more complex effects, being positive for offline participation $\left(\beta_{\mathrm{RA}}=.010, \beta_{\mathrm{RB}}=.007 \mathrm{p}<.001\right.$ ) but being mediated by social media mobilisation for online participation $\left(\beta_{\mathrm{RA}}=.007 p<.01\right)$. Post-estimation tests indicate $(F(1,1972)=2.92$ for offline and $F=3.52$ for online) significantly stronger effects of extrinsic motivations over intrinsic motivations (in both models A), it remains significant for online participation but becomes non-significant for the offline participation (model $B$ ). Hypothesis 1 is thus only partially confirmed, as extrinsic motivations remains stable for both online and offline participation regardless of other factors, however intrinsic motivations lose their explanatory power for online activities once mediated by mobilisation efforts. Hypothesis $2 a$ is not confirmed as it is extrinsic motivations, for both offline and online sphere, which have a greater explanatory power $(\mathrm{H} 2 b)$.

The path analysis (Figures 1 and 2) offers a somewhat different perspective of the interplay between motivations and mobilisation factors. Again the higher explanatory power of extrinsic motivations is borne out, with intrinsic motivations for online forms of participation lacking significance while mediated (this refutes Hypothesis 3a). Therefore it appears that across all forms of political participation, people seek approval from others (in line with the $\mathrm{H} 3 \mathrm{~b}$ ) rather than personal fulfilment. Feelings of personal efficacy or 'feeling good' are less significant in explaining online political engagement than 'group belonging' incentives. In many ways this is logical as it suggests that politics is a prosocial activity driven by a desire to have an impact on others as well as gaining rewards and recognition. Therefore, political participation might elicit positive feelings that lead to stronger intrinsic motivations however extrinsic motivations have the greater explanatory power. Furthermore while there is an indication that offline political participation is likely to be influenced by both intrinsic and extrinsic motivations, online participation may be motivated primarily by seeking acceptance from other online users. 


\section{Social media mobilisation}

Mobilisation through social media is discussed as having the potential to revitalise democratic participation. Comparing the simple average of the mobilization messages received by those who decided to engage (even in one, regardless of which, sphere of political activity) in comparison to those who remained passive, we see that on average those participating were twice as likely to have been mobilised (for passive: messages received from parties $M=.68$, from campaigning organization $M=.77$, from peers $M=.83$; for active: messages received from parties $M=1.74$, from organizations $M=2.03$, from peers $M=1.92)$. The data on the potential effect of mobilisation via social media shows campaigning organizations' messages have the strongest effects on both offline $\left(\beta_{p}=.210\right.$ $p<.000)$ and online $\left(\beta_{p}=.330 p<.000\right)$ activities. Although with significantly lower impact, peers seem to have minimal influence on both activities $\left(\beta_{p}=.059 p<.1\right.$ for offline and $\beta_{P}=.098 p<.05$ for online). Surprisingly, encouragement received through social media from political parties has a weak, almost non-significant, positive effect $\left(\beta_{P}=.057 p=.096\right)$ on offline participation, while the effect is statistically non-significant for online participation (with a negative direction).

We would argue that different sources having differing levels of influence, with campaigning organizations having a solid and stable impact. One might explain the differential influence levels by variances in the ties social media users have with political parties, campaign organizations and friends. We assume that to receive encouragement from any social media actors one needs to be connected into their network directly or via friends. It seems to be rare (with the exception for some specific cases e.g. journalists, partisans or potential trolls) that the average citizen would connect via social media (so providing an endorsement and giving the organization permission to contact them as well as being able to interact with the organization's profile through likes, shares or comments) with organizations that she/he is not supporting (thus one may visit contra-ideological groups without leaving any trace of such visits).

As for political party activists, they represent a small minority and party encouragements only circulate within bounded and homogenous networks. While within the context of an election party communication might be visible outside these networks, non-activists may be unwilling to engage with this because their network is largely non-partisan and so party-driven campaign may be perceived as unacceptable (Pattie \& Johnson, 2009; Matthes, 2013). On the contrary, non-partisan campaign organizations' campaigns lack, in most cases, the controversial and divisive partisan nature. These organizations also attempt to build broad communities and encourage the widest number of people to participate in online deliberation 
(commenting) or viral marketing (following or sharing) (Vesnic-Alujevic, 2012). The greater credibility and inclusive strategy may enable campaign organizations to extend their reach, gain credibility and have an impact on the media or public agenda (Norris \& Curtice, 2008). As a consequence, the visibility campaign organizations gain demonstrates their social importance and level of support (Stefanone et al., 2012) driving further demonstrations of support. Hence, campaign organisations are most likely to encourage supporters to participate in offline engagement as well as building a large and engaged online audience. Our analysis confirms that the encouragement from campaign organizations is the most significant mediator.

The weaker mediating power of the messages received from social media friends is surprising (Bond et al., 2012), however may be explained by the fact that social media users inhabit fairly heterogeneous communities, where one can be friends regardless of levels of agreement on political issues, even though un-friending during a public opinion flashpoint is an emerging phenomenon (John \& Dvir-Gvirsman, 2015). Therefore while one may see countervailing political messages, unless there is strong trust that disagreeing will not end the friendship or lead to hostility such encouragements will be more likely to be ignored (Matthes, 2013). Furthermore, if the network is highly heterogeneous friends may simultaneously send conflicting political messages thus neutralizing one another; as a consequence friends' encouragements may have a lesser impact on political activity (Valenzuela et al., 2012).

The low impact of political parties messages raises a question if, in fact, political parties focus almost exclusively on encouraging offline forms of participation, for example getting out their vote, especially during an election campaign, as well as encouraging their online supporters to join the party. Conversely, we know UK parties encourage sharing, if not debating (Author, 2014), but their networks, and particularly the number of activists in their networks are no more than 7,000 individuals (Author, 2016), therefore parties may lack the reach of campaign organisations as parties may have lower numbers of committed supporters. Alternatively, it is possible that low trust in political parties mediates the effect of their communication. Equally, as suggested earlier, social media users may not post partisan material for fear of receiving negative responses from within their heterogeneous and largely non-partisan social networks. Given the complexity it is impossible to test for all variables, however regardless of the causes, the weak or non-existent power of political parties in encouraging political participation confirms the complex relationship between social media users, their intrinsic and extrinsic motivations and those who seek to spur them to action via social media. 


\section{Discussion}

Our findings show, consistent with Hypothesis 1, that regardless of the form or sphere of participation intrinsic and extrinsic motivations combined exert a positive influence on political participation. However contrary to Hypothesis 2 we did not identify different motivations within the different spheres, rather we found extrinsic motivations were the most significant drivers of participation regardless of the sphere. This finding suggests that the online and offline spheres may not be as different as some expect (Vissers \& Stolte, 2014). Participation in both spheres are best explained by extrinsic motivational factors, although offline participation is more self-fulfilling while online participation appears to be concerned more with fitting in. Fitting in may offer some degree of fulfilment, suggesting that there may still be a link between intrinsic and extrinsic motivational factors (Ryan \& Deci, 2000b). However, in evidencing that extrinsic motivations have greater explanatory power over participation occurring within the online sphere we can suggest that some of this behaviour is simple clicktivism: behaviour resulting from mobilisation but having little personal significance. While mobilisation does not increase the power of motivations, and in particular appears to have a negative effect on intrinsic motivations, we suggest that the mobilisation tactics pursued by political parties, campaign organisations and peers still have some effect in determining whether people participate in civically-oriented activities. However, within the online sphere, some social media users may follow a cue from campaign organisations, parties or peers in order to gain acceptance, such as a like from members of the network providing they feel the message will resonate with those who follow them (Deci et al., 1999; Vallerand \& Lalande, 2011). This finding supports Hypothesis $3 \mathrm{~b}$, although the finding is strongest for campaign organisations.

Intrinsic and extrinsic motivations, as previous studies suggest, play a complex role in influencing decisions to participate (Madden et al., 1992; Ryan \& Deci, 2000b). However, within a UK political context it appears extrinsic motivations predominate (Grant, 2008; Omoto et al., 2010). Political activism is conducted to benefit others as well as to receive rewards and recognition (Degli-Antoni, 2009). But, realising goals and gaining recognition may well contribute to stronger intrinsic motivations that underpin a propensity to participate further. Arguably campaign organisations are most successful in using social media to offer the incentives most likely to mobilise their supporters. Through building communities they may inculcate positive motivations so that at the point of asking they are most successful in gaining positive responses to their requests. The persuasive power of campaign organisations may also result from their constant communication with supporters, unlike parties who are most active during elections and peers who may be sporadically active politically. However, at the point of acting online, the most important consideration may be 
whether the action fits to the norms of behaviour within a network; offline however involves also seeking self-fulfilment as well as gaining recognition.

Campaign organisations do not simply reinforce extrinsic motivations for offline political participation however. Without in-depth research among individuals or a longitudinal panel study it is impossible to determine whether mobilisation strategies over time have a cumulative impact on the propensity to act. However, what our data may give an indication of is that campaign organisations not only encourage actions from their committed followers in order to spread the word but they can also encourage the belief that any action can simultaneously have a positive impact within the real world as well as on the individual through earning recognition and rewards. Hence messages that provide extrinsic motivations to act might, longer-term, and through the process of taking part in a collective action, contribute to strengthening intrinsic motivations by making who act feel good about themselves and gain a greater sense of self-efficacy (Vraga et al., 2015). Therefore campaign organizations have the propensity to channel the enthusiasm of the committed while also recruiting participants with low motivations who may be encouraged to act through accidental exposure. But both committed and single click-based groups may be spurred into pursuing a broader and deeper suite of participation that may lead to a deeper commitment to civically-oriented activity. Social media provides a space for organisations to communicate to a wide community, attract users to their communities and encourage actions; it also provides a space where users can dabble in activism. Our data suggests if there is some level of motivation and the right cue social media can provide a pathway into civic participation, but in the battle for hearts and action, campaign organisations have the edge in providing this pathway.

\section{Limitations}

As with any study based on a single country, cross-sectional survey, while there was a vibrant political culture in the lead up to the 2015 general election and significant debates surrounding the future of the union of nations, the relationship with the European Union and the best way to ameliorate the long-lasting effects of the global recession, there are limits to the generalizability of the result for other countries. A panel study would be required in order to control for pure effects and the temporal consistency of motivations and mobilisation effects on political participation. The political context may also have led to somewhat higher levels of engagement, as well as higher levels of encouragement from a range of organizations and actors which might not be witnessed during a non-election period, especially from electoral organizations. Therefore we might suggest that some findings are exaggerated or that encouragement from friends via social media, in non-electoral periods, 
may play a more important role. In other words there are a number of communication and context variables that cannot be controlled for but which might impact on the results.

The survey was also designed to ask about the respondents' motivations for each individual form of participation. This produces two limitations, firstly the lack of a general question regarding the likelihood to participate regardless of the activity (so measuring holistically the propensity to be active). Secondly, given that the survey measured motivations for each individual action, when aggregated we lose the individual context of the data where any given action may have unique drivers. However, the consistency of results suggests we provide unique insights into the relationship between motivations, mobilisation strategies and behaviour which can form the basis for further research.

A more sophisticated question relates to the receipt of encouragement from other means beyond social media. It was impossible to conceive of all the means by which campaign organizations, political parties or friends are able to interact with citizens in an attempt to mobilize them. We thus focused entirely on social media in this project, but with the understanding that any participation not explained by these forms of encouragement could arrive from other sources. Equally, even when considering social media as a prime route for persuasive communication, it may be the case that the relative homogeneity of the networks individuals inhabit may be a mediating factor on whether communication, in particular from friends, has a significant effect. However, overall, we find some interesting suggested routes to participation and indications of the power of differing sets of motivations. In particular the significance of the direct motivational pathways to participation may indicate that intrinsic and extrinsic motivations are strong predictors of political participation. If these findings appear controversial it is necessary to conduct further research to focus on these and other mediating factors, drawing on broader psycho-social perspectives (Klöckner, 2013) in order to provide even more holistic explanations for the variety of forms of political participation facilitated in the $21^{\text {st }}$ Century. 


\section{References}

Asencio, H., \& Sun, R. (2015). Cases on Strategic Social Media Utilization in the Nonprofit Sector. IGI Global.

Bimber, B., \& Copeland, L. (2013). Digital media and traditional political participation over time in the US. Journal of Information Technology \& Politics, 10(2), 125-137.

Condon, M., \& Holleque, M. (2013). Entering Politics: General Self-Efficacy and Voting Behavior Among Young People. Political Psychology, 34(2), 167-181.

Deci, E. L. (1971). Effects of externally mediated rewards on intrinsic motivation. Journal of personality and Social Psychology, 18(1), 105-115.

Deci, E. L., Koestner, R., \& Ryan, R. M. (1999). A meta-analytic review of experiments examining the effects of extrinsic rewards on intrinsic motivation. Psychological bulletin, 125(6), 627-668.

Degli-Antoni, G. (2009). Intrinsic vs. extrinsic motivations to volunteer and social capital formation. Kyklos, 62(3), 359-370.

De Zúñiga, H. G., Puig-I-Abril, E., \& Rojas, H. (2009). Weblogs, traditional sources online and political participation: An assessment of how the Internet is changing the political environment. New media \& society, 11(4), 553-574.

De Zúñiga, H. G., \& Valenzuela, S. (2011). The mediating path to a stronger citizenship: Online and offline networks, weak ties, and civic engagement. Communication Research, 38(3), 397-421.

De Zúñiga, H. G., Jung, N., \& Valenzuela, S. (2012). Social media use for news and individuals' social capital, civic engagement and political participation. Journal of ComputerMediated Communication, 17(3), 319-336.

De Zúñiga, H. G., Molyneux, L., \& Zheng, P. (2014). Social media, political expression, and political participation: Panel analysis of lagged and concurrent relationships. Journal of Communication, 64(4), 612-634.

Diehl, T., Weeks, B. E., \& de Zúñiga, H. G. (2015). Political persuasion on social media: Tracing direct and indirect effects of news use and social interaction. New Media \& Society, 1461444815616224.

Di Gennaro, C., \& Dutton, W. (2006). The Internet and the public: Online and offline political participation in the United Kingdom. Parliamentary Affairs,59(2), 299-313.

Dutta-Bergman, M. J. (2006). Community participation and Internet use after September 11: Complementarity in channel consumption. Journal of Computer-Mediated Communication, 11(2), 469-484.

Ekdale, B., Namkoong, K., Fung, T. K., \& Perlmutter, D. D. (2010). Why blog?(then and now): Exploring the motivations for blogging by popular American political bloggers. New Media \& Society, 12(2), 217-234. 
Enjolras, B., Steen-Johnsen, K., \& Wollebæk, D. (2013). Social media and mobilization to offline demonstrations: Transcending participatory divides? New Media \& Society, 15(6), 890-908.

Enli, G. S., \& Skogerbø, E. (2013). Personalized campaigns in party-centred politics: Twitter and Facebook as arenas for political communication. Information, Communication \& Society, 16(5), 757-774.

Fisher, J., Fieldhouse, E., \& Cutts, D. (2014). Members are not the only fruit: Volunteer activity in British political parties at the 2010 general election. The British Journal of Politics \& International Relations, 16(1), 75-95.

Gibson, R., \& Cantijoch, M. (2013). Conceptualizing and measuring participation in the age of the internet: Is online political engagement really different to offline?. The Journal of Politics, 75(03), 701-716.

Grant, A. M. (2008). Does intrinsic motivation fuel the prosocial fire? Motivational synergy in predicting persistence, performance, and productivity. Journal of applied psychology, 93(1), 48-58.

Guo, C., Saxton, G. (2014) "Tweeting social change: How social media are changing nonprofit advocacy”, Nonprofit and voluntary sector quarterly. 43(1): 57-79.

Hirzalla, F., Van Zoonen, L., \& de Ridder, J. (2010). Internet use and political participation: Reflections on the mobilization/normalization controversy. The Information Society, 27(1), 115.

Huckfeldt, R. (2014). Networks, contexts, and the combinatorial dynamics of democratic politics. Political Psychology, 35(S1), 43-68.

John, N. A., \& Dvir-Gvirsman, S. (2015). “I Don't Like You Any More”: Facebook Unfriending by Israelis During the Israel-Gaza Conflict of 2014.Journal of Communication, 65(6), 953974.

Kim, Y., Chen, H. T., \& de Zúñiga, H. G. (2013). Stumbling upon news on the Internet: Effects of incidental news exposure and relative entertainment use on political engagement. Computers in Human Behavior, 29(6), 2607-2614.

Klar, M., \& Kasser, T. (2009). Some Benefits of Being an Activist: Measuring Activism and Its Role in Psychological Well-Being. Political Psychology, 30(5), 755-777.

Klöckner, C. A. (2013). A comprehensive model of the psychology of environmental behaviour-A meta-analysis. Global Environmental Change,23(5), 1028-1038.

Kriesi, H. (2008). Political mobilisation, political participation and the power of the vote. West European Politics, 31(1-2), 147-168.

Leighley, J. E. (1995). Attitudes, opportunities and incentives: A field essay on political participation. Political Research Quarterly, 48(1), 181-209.

Lowndes, V. (2004). Getting on or getting by? Women, social capital and political participation. The British Journal of Politics \& International Relations, 6(1), 45-64. 
Lupton, R. N., Singh, S. P., \& Thornton, J. R. (2014). The moderating impact of social networks on the relationships among core values, partisanship, and candidate evaluations. Political Psychology. 36(4), 399-414.

Madden, T. J., Ellen, P. S., \& Ajzen, I. (1992). A comparison of the theory of planned behavior and the theory of reasoned action. Personality and social psychology Bulletin, 18(1), 3-9.

McClurg, S. D. (2003). Social networks and political participation: The role of social interaction in explaining political participation. Political research quarterly, 56(4), 449-464.

Nam, T. (2012). Dual effects of the internet on political activism: Reinforcing and mobilizing. Government Information Quarterly, 29, 90-97.

Omoto, A. M., Snyder, M., \& Hackett, J. D. (2010). Personality and motivational antecedents of activism and civic engagement. Journal of Personality, 78(6), 1703-1734.

Panagopoulos, C. (2013). Positive Social Pressure and Prosocial Motivation: Evidence from a Large-Scale Field Experiment on Voter Mobilization. Political Psychology, 34(2), 265-275.

Park, N., Kee, K. F., \& Valenzuela, S. (2009). Being immersed in social networking environment: Facebook groups, uses and gratifications, and social outcomes.

CyberPsychology \& Behavior, 12(6), 729-733.

Polat, R. K. (2005). The Internet and political participation exploring the explanatory links. European journal of communication, 20(4), 435-459.

Quintelier, E., \& Vissers, S. (2008). The effect of Internet use on political participation an analysis of survey results for 16-year-olds in Belgium. Social Science Computer Review, 26(4), 411-427.

Rosenstone, S. J., \& Hansen, J. M. (1993). Mobilization, participation, and democracy in America. New York, NY: Macmillan.

Ryan, R. M., \& Deci, E. L. (2000a). Self-determination theory and the facilitation of intrinsic motivation, social development, and well-being. American psychologist, 55(1), 68.

Ryan, R. M., \& Deci, E. L. (2000b). Intrinsic and extrinsic motivations: Classic definitions and new directions. Contemporary educational psychology, 25(1), 54-67.

Semaan, B., Faucett, H., Robertson, S., Maruyama, M., \& Douglas, S. (2015, February). Navigating Imagined Audiences: Motivations for Participating in the Online Public Sphere. In Proceedings of the 18th ACM Conference on Computer Supported Cooperative Work \& Social Computing (pp. 1158-1169). ACM. Chicago

Shang, R. A., Chen, Y. C., \& Shen, L. (2005). Extrinsic versus intrinsic motivations for consumers to shop on-line. Information \& Management,42(3), 401-413.

Sotirovic, M. \& McLeod, J. M. (2001). Values, communication behavior, and political participation. Political Communication, 18(3), 273-300. 
Stanley, J. W., \& Weare, C. (2004). The effects of internet use on political participation evidence from an agency online discussion forum. Administration \& Society, 36(5), 503-527.

Swanson, D. L., \& Mancini, P. (1996). Politics, media, and modern democracy: An international study of innovations in electoral campaigning and their consequences. London: Greenwood.

Tang, G., \& Lee, F. L. (2013). Facebook use and political participation: The impact of exposure to shared political information, connections with public political actors, and network structural heterogeneity. Social Science Computer Review, 31(6), 763-773.

Theocharis, Y. (2015). The conceptualization of digitally networked participation. Social Media+Society, 1(2), 2056305115610140.

Vaccari, C. (2013). Digital politics in Western democracies: a comparative study. JHU Press.

Valeriani, A., \& Vaccari, C. (2015). Accidental exposure to politics on social media as online participation equalizer in Germany, Italy, and the United Kingdom. new media \& society, 1461444815616223.

Vallerand, R. J., \& Lalande, D. R. (2011). The MPIC Model: The perspective of the hierarchical model of intrinsic and extrinsic motivation. Psychological Inquiry, 22(1), 45-51.

Vissers, S., \& Stolle, D. (2014). The Internet and new modes of political participation: online versus offline participation. Information, Communication \& Society, 17(8), 937-955.

Vraga, E. K., Anderson, A. A., Kotcher, J. E., \& Maibach, E. W. (2015). Issue-Specific Engagement: How Facebook Contributes to Opinion Leadership and Efficacy on Energy and Climate Issues. Journal of Information Technology \& Politics, (just-accepted).

Ward, S., Gibson, R., \& Lusoli, W. (2003). Online participation and mobilisation in Britain: Hype, hope and reality. Parliamentary affairs, 56(4), 652-668.

Weeks, B. E., Ardèvol-Abreu, A., \& de Zúñiga, H. G. (2015). Online Influence? Social Media Use, Opinion Leadership, and Political Persuasion. International Journal of Public Opinion Research.

Zhao, X., Lynch, J. and Chen Q. (2010) Reconsidering Baron and Kenny: Myths and Truths about Mediation Analysis. The Journal of Consumer Research, Vol. 37, No. 2, pp. 197-206. 
Table 1: Regressions analysis for offline and online political participation

\begin{tabular}{|c|c|c|c|c|c|c|c|c|}
\hline \multirow[b]{2}{*}{ SES } & \multicolumn{2}{|c|}{$\begin{array}{c}\text { Offline } \\
\text { Model A }\end{array}$} & \multicolumn{2}{|c|}{$\begin{array}{c}\text { Offline } \\
\text { Model B }\end{array}$} & \multicolumn{2}{|c|}{$\begin{array}{c}\text { Online } \\
\text { Model A }\end{array}$} & \multicolumn{2}{|c|}{$\begin{array}{c}\text { Online } \\
\text { Model B }\end{array}$} \\
\hline & & & & & & & & \\
\hline Gender & -.017 & & -.031 & & .067 & $*$ & .048 & \\
\hline Age & .003 & $* *$ & .006 & $* * *$ & -.000 & & .001 & \\
\hline University grade & .174 & $* * *$ & .155 & $* * *$ & .171 & $* * *$ & .145 & $* * *$ \\
\hline Social grade & -.027 & $* *$ & -.025 & $* *$ & .019 & & .021 & $\dagger$ \\
\hline Employed & .034 & & .015 & & -.014 & & -.035 & \\
\hline \multicolumn{9}{|l|}{ Political variables } \\
\hline Party proximity & .196 & $* * *$ & .153 & $* * *$ & .164 & $* * *$ & .134 & $* * *$ \\
\hline Discuss politics & .371 & $* * *$ & .344 & $* * *$ & .451 & $* * *$ & .401 & $* * *$ \\
\hline \multicolumn{9}{|l|}{ Motivations } \\
\hline Intrinsic & .010 & $* * *$ & .006 & $* *$ & .007 & $* *$ & .001 & \\
\hline Extrinsic & .018 & $* * *$ & .011 & $* * *$ & .019 & $* * *$ & .012 & $* * *$ \\
\hline \multicolumn{9}{|l|}{ SM Encouragement } \\
\hline from Political party & & & .049 & $* *$ & & & .018 & \\
\hline from campaign organization & & & .120 & $* * *$ & & & .206 & $* * *$ \\
\hline from friends & & & .026 & & & & .003 & \\
\hline Constant & -.626 & $* * *$ & -.673 & $* * *$ & -.505 & $* * *$ & -.526 & $* * *$ \\
\hline Adj R2 & .332 & & .377 & & .298 & & .362 & \\
\hline
\end{tabular}

Note: OLS regression (robustness check by Poisson and negative binomial model: with the difference only for social grade being not statistically significant), Sample size $\mathrm{N}=1982,+<.1,{ }^{*} \mathrm{p}<.05 * * \mathrm{p}<.01, * * * \mathrm{p}<.001$. VIF: offline A 1.50; offline B 1.61; online A 1.43; online B 1.57 
Figure 1: Path analysis of the motivations and encouragements on offline political participation

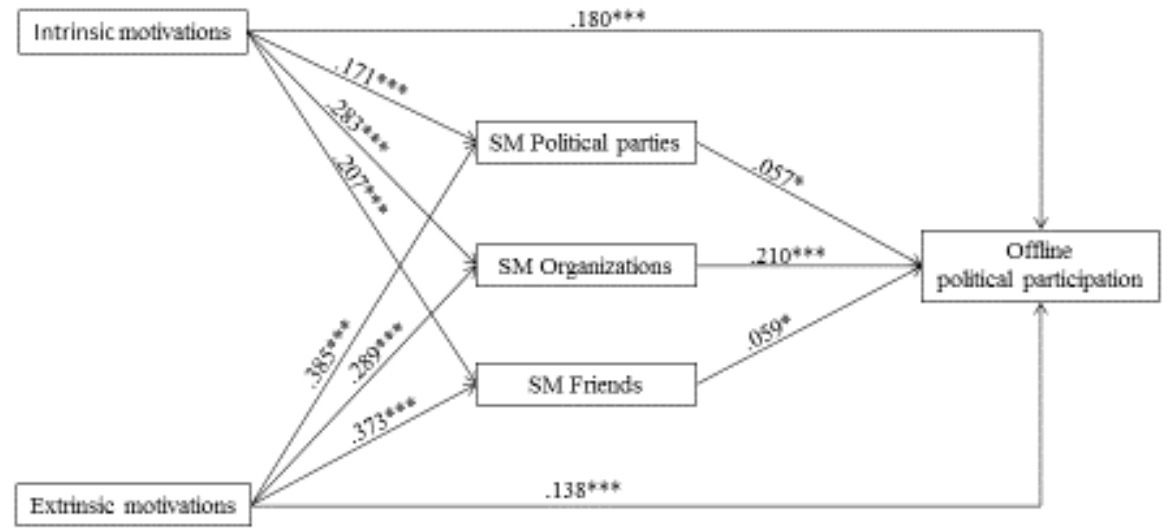

NOTE: Sample size N=1982. Path entries are standardized SEM coefficients $(\beta) * * * p<.001 * * p<.05 * \mathrm{p}<.1$ based on two-tailed Sobel test, bootstrap at a level of 2000 iterations. The model controls for effects of sociodemographic characteristics (age, gender, social class, employment, education) on exogenous and endogenous variables. Model goodness of fit: CMIN/DF = 3.000; CFI=.998; RMSEA=.032; PCLOSE $=.994 . \mathrm{R}_{\text {offline participation }}^{2}=.34$

Figure 2: Path analysis of the motivations and encouragements on online political participation

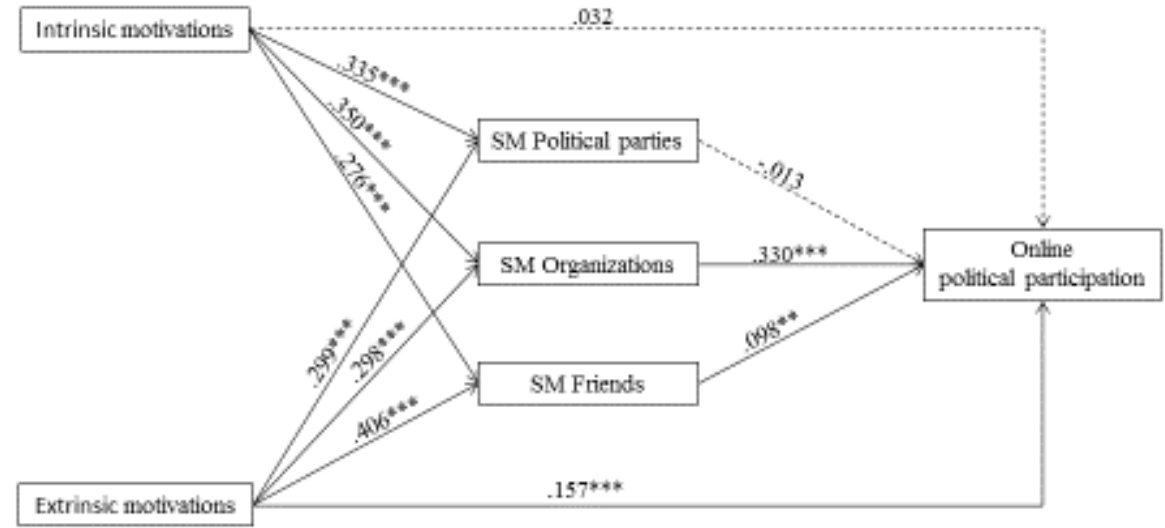

NOTE: Sample size N=1982. Path entries are standardized SEM coefficients $(\beta) * * * \mathrm{p}<.001{ }^{* *} \mathrm{p}<.05$ based on two-tailed Sobel test, bootstrap at a level of 5000 iterations. The model controls for effects of sociodemographic characteristics (age, gender, social class, employment, education) on exogenous and endogenous variables. Model goodness of fit: CMIN/DF = 3.655; CFI=.997; RMSEA=.037; PCLOSE $=.968 . \mathrm{R}_{\text {online participation }}^{2}=.31$ 
Table 2: Effects of motivations and mobilisation via social media on political participation

\begin{tabular}{|c|c|c|c|c|c|}
\hline \multirow{5}{*}{ Intrinsic motivations } & & Direct no mediator & $\rightarrow$ & \multirow{10}{*}{ Offline political participation } & $.258 * * *$ \\
\hline & & Direct with mediator & $\rightarrow$ & & $.180^{* * *}$ \\
\hline & $\rightarrow$ & SM Party & $\rightarrow$ & & $.010^{* * *}$ \\
\hline & $\rightarrow$ & SM Organization & $\rightarrow$ & & $.059 * * *$ \\
\hline & $\rightarrow$ & SM Friends & $\rightarrow$ & & $.012 * * *$ \\
\hline \multirow{5}{*}{ Extrinsic motivations } & & Direct no mediator & $\rightarrow$ & & $.239 * * *$ \\
\hline & & Direct with mediator & $\rightarrow$ & & $.138 * * *$ \\
\hline & $\rightarrow$ & SM Party & $\rightarrow$ & & $.022 * *$ \\
\hline & $\rightarrow$ & SM Organization & $\rightarrow$ & & $.061 * * *$ \\
\hline & $\rightarrow$ & SM Friends & $\rightarrow$ & & $.022 * * *$ \\
\hline \multirow{5}{*}{ Intrinsic motivations } & & Direct no mediator & $\rightarrow$ & \multirow{10}{*}{ Online political participation } & $.168 * * *$ \\
\hline & & Direct with mediator & $\rightarrow$ & & .032 \\
\hline & $\rightarrow$ & SM Party & $\rightarrow$ & & -.004 \\
\hline & $\rightarrow$ & SM Organization & $\rightarrow$ & & $.115^{* * *}$ \\
\hline & $\rightarrow$ & SM Friends & $\rightarrow$ & & $.027 * * *$ \\
\hline \multirow{5}{*}{ Extrinsic motivations } & & Direct no mediator & $\rightarrow$ & & $.285 * * *$ \\
\hline & & Direct with mediator & $\rightarrow$ & & $.157 * * *$ \\
\hline & $\rightarrow$ & SM Party & $\rightarrow$ & & -.004 \\
\hline & $\rightarrow$ & SM Organization & $\rightarrow$ & & $.098 * * *$ \\
\hline & $\rightarrow$ & SM Friends & $\rightarrow$ & & $.040 * * *$ \\
\hline
\end{tabular}
NOTE: Standardized regression coefficient multiplied by the effect of independent variable on mediator and mediator on dependent variable, with the
exception for 'no mediation' coefficient. Sobel test of significance for indirect effects 2 -tailed $* * \mathrm{p}<.05, * * * \mathrm{p}>.001$ 


\section{Appendix}

Table 1: Spearman's Rho correlations among different political online and offline activities

Boycotted a company or product Contacted an elective representative Joined a political party

Follow political party/MP/candidate on SM

\begin{tabular}{|c|c|c|}
\hline $\begin{array}{l}\text { Demonstra } \\
\text { tion }\end{array}$ & Boycott & Contact \\
\hline$\rho=.398^{*}$ & & \\
\hline $.421^{*}$ & $.346^{*}$ & \\
\hline $.585^{*}$ & $.359^{*}$ & $.431^{*}$ \\
\hline $.271^{*}$ & $261^{*}$ & $.315^{*}$ \\
\hline $.239^{*}$ & $.353^{*}$ & $.334^{*}$ \\
\hline $.268^{*}$ & $.297^{*}$ & $.276^{*}$ \\
\hline $.216^{*}$ & $.303^{*}$ & $.253^{*}$ \\
\hline
\end{tabular}

Joined Follow Follow Shared party party NGO content

Follow political NGO on SM

Shared political content on SM

Commented about politics on SM

NOTE Spearman's Rho correlations, statistical significance * $\mathrm{p}<.000$ 2-tailed

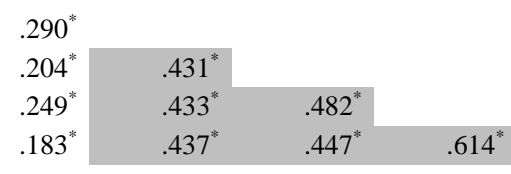

Appendix Table 2: Indexes of offline and online political participation

\begin{tabular}{lcc} 
& CFA & CFA \\
& Online & Offline \\
Commented about politics on SM & .682 & \\
Shared political content on SM & .648 & \\
Follow political NGO on SM & .737 & \\
Follow political party/MP/candidate on SM & .620 & \\
Joined a political party & & .555 \\
Taken part in a demonstration & .575 \\
Contacted an elective representative & .737 \\
Boycotted a company or product & .688 \\
\hline Note: for CFA standardized estimates are indicated. Cronbach alpha: offline .782 online .714; CFI = .986; RMSEA =.046; PCLOSE $=.706$
\end{tabular}

